\title{
Depressive symptoms in elderly living only or accompanied: the impact of hearing protection
}

\begin{abstract}
Objective: To determine the impact of hearing protection on a group of elderly people with depressive signs, whether they live alone or accompanied.

Method: This is an exploratory descriptive study carried out with 80 elderly users of hearing aids and with signs of depression. WHOQOL-Bref and the Geriatric Depression Scale Were applied before and after adapting to the hearing aid. All subjects were audiologically evaluated. Sample was divided into two groups, those who live alone and those who live accompanied.

Results: Depressive signs were recorded in both groups; Most of the samples reported having a good quality of life, and there was no significant change in this result after adapting to the hearing aid. Despite this, qualitative data analysis showed improvement in quality of life $(10 \%)$ and better mood (15\%); Living alone or accompanied did not significantly influence the results.
\end{abstract}

Conclusion: The presence of depressive signs was important, regardless of subjects living alone or accompanied The use of hearing aids did not significantly influence the quality of life of the studied group.

Keywords: elderly, hearing, deafness, depression, hearing assistants, quality of life
Volume 2 Issue I - 2017

\author{
Marta Braga,' Angela Ribas, ${ }^{2}$ Claudia \\ Moretti,' Giselle Massi,' Jackeline Martins,' \\ Marine Raquel Rosa, ${ }^{3}$ Renato Riesembrg' \\ 'Tuiuti University of Paraná, Brazil \\ ${ }^{2}$ Department of Phonoaudiology, Tuiuti University of Paraná, \\ Brazil \\ ${ }^{3}$ Federal University of Paraíba, Brazil
}

Correspondence: Angela Ribas, Department of Phonoaudiology, Tuiuti University of Paraná, Canter of Audition and Language, Curitiba, Brazil, Email Angela.ribas@utp.br

Received: June 19,2017 | Published: August II, 2017

\section{Introduction}

According to the World Health Organization, the high and increasing prevalence of depression in different populations all over the world as well as the impact it produces, configure the disease as one of the most serious public health problems in the early twentyfirst century. ${ }^{1}$

The prevalence of depression is distributed unevenly in the population. ${ }^{2}$ However, there are reports in the literature that indicate that there is a significant association between depression and aging ${ }^{3-6}$ depression and chronic diseases; and depression and hearing loss. ${ }^{7}$ It is known that aging occurs naturally, a decrease in the functional capacity of various organs and tissues, increasing the risks of onset of chronic-degenerative diseases. Among these diseases, it has been accompanied by the presence of presbycusis, or the decrease or loss of hearing acuity in older people. ${ }^{3,8}$

Hearing loss caused by presbycusis, if not adequately treated, can contribute considerably to the isolation and loss of social relationships, since hearing difficulties and restricted access to oral language distract the elderly from their friends and family, restricting their interactions socio-verbal. ${ }^{9}$ It is known to interact with others is essential to ensure quality of life and well - being of older people, in this sense, the use of hearing aids can benefit the autonomy and independence of the elderly with hearing loss. ${ }^{10}$

According to the National Health Policy for the Elderly ${ }^{11}$ the entire population segment with more than 60 years, which has functional dependencies, need to gain visibility in the various levels of health care. Thus, it states that it is necessary to create physical, social and attitudinal environments capable of improving the health of older people with difficulties or disabilities, in order to increase their participation in the communities in which they are inserted.
Considering these assumptions, the objective of this study was to determine the impact of hearing protection in a group of elderly people with depressive signs, considering the fact that they live alone.

\section{Materials and methods}

This descriptive study is part of longitudinal research, approved by the Ethics Committee under number UTP-027/2008. All participants were individually given the Free and Informed Consent Form, containing information about the nature of the study, the voluntary nature of their participation and the complete privacy of their identity. Data collection occurred between August 2013 and August 2014.

The subjects of this research, in the total of 40 elderly people who were accompanied and 40 who lived alone, were randomly selected in a Clinic of Speech-Language Pathology and Audiology accredited by SUS to provide service in the area of hearing health, in the city of Curitiba-PR.

We included individuals over 60 years of age, with hearing loss, effective users of hearing aids for at least six months. Subjects who did not understand the terms of the study were excluded from the study.

All participants underwent 3 phases of the research: Phase 1-application of protocol for identification data and threshold audiometry examination, performed at the initial consultation. Phase 2 - quality of life WHOQOL-Bref ${ }^{12}$ and inventory survey of depressive signs Geriatric Depression Scale (GDS) ${ }^{13}$ 1999) held in the query to test hearing aids. Phase 3 - reapplication of WHOQOL-Bref and GDS in the semi-annual consultation of monitoring and verification of the hearing aid in the service.

The results of the audiometry were analyzed according to the type, degree, and configuration of hearing loss. ${ }^{14}$ The GDS results were summed, categorized and analyzed according to the following 
gradations: zero to 5 points - no depressive signs; 6 to 11 points - with depressive signs; above 11 points - severe depression. ${ }^{13}$ The results of the WHOQOL-Bref were added, categorized and analyzed according to the following classification: very poor quality of life, poor, average, good and very good. ${ }^{12}$ All subjects who presented depressive signs were referred to the Clinic of Psychology of the institution where the research was performed, after the data collection was completed. The data were typed in spreadsheet and received statistical treatment using the difference of proportions test, at a significance level of $0.05 \%$.

\section{Results}

The characterization of the sample, with respect to age, gender and way of life, educational level and occupational situation are shown in Table 1.

Table I Characterization of the sample by gender, age, martital status degree of instruction and occupational situation, considering the variable "way of life" $(\mathrm{N}=80)$

\begin{tabular}{lll}
\hline Variable & $\begin{array}{l}\text { Live alone } \\
(\mathbf{N}=40)\end{array}$ & $\begin{array}{l}\text { Lives together } \\
(\mathbf{N}=\mathbf{4 0 )}\end{array}$ \\
$\mathbf{N}$ & $\mathbf{N}$ & $\%$ \\
\hline
\end{tabular}

\section{Gender}

Female

Male

22

55

25

Age

60 To 65 Years

66 To 70 Years

18

45

15

70 To 75 Years

76 Or More

10

25

7

17.5

Marital Situation

Not Married

Married

$$
6
$$

13

32.5

$12 \quad 30$

14

35

12

30

6

15

\section{Widower}

Separated / Divorced

$\begin{array}{llll}3 & 7.5 & 2 & 5 \\ 23 & 57.5 & 26 & 65 \\ 9 & 22.5 & 11 & 27.5 \\ 5 & 12.5 & 1 & 2.2\end{array}$

Degree of Education

\begin{tabular}{lllll} 
Non-Literate & I & 2.5 & 4 & 10 \\
Ist Grade Incomplete & 12 & 30 & 13 & 32.5 \\
Ist Grade & 18 & 45 & 12 & 30 \\
Incomplete 2nd Grade & 0 & 0 & 2 & 5 \\
2nd Grade & 5 & 12.5 & 7 & 17.5 \\
Superior & 4 & 10 & 2 & 5 \\
Occupation & & & & \\
In Activity & 15 & 37.5 & 18 & 45 \\
Retired & 25 & 62.5 & 22 & 55 \\
\hline
\end{tabular}

The predominant hearing loss was bilateral $(80 \%)$, sensorineural type $(93 \%)$, moderate degree $(85 \%)$ and descending configuration $(83 \%)$, characteristic of presbycusis. The majority of the sample used prosthesis in both ears $(85 \%)$ retroauricular type $(60 \%)$. The presence of depressive signs was verified in the sample studied. Table 2 presents the GDS results comparing the period before and after the adaptation of the hearing aid. Through the difference-of-proportions test, comparing the groups Vive solo and Vive accompanied, at a significance level of 0.05 , it was verified that there was no significant difference in any of the cases. In the before and after comparison of the prosthesis there were also no significant differences.

Table 2 Comparison of total GDS results

\begin{tabular}{|c|c|c|c|c|c|}
\hline \multirow[t]{2}{*}{$\begin{array}{l}\text { Depressive } \\
\text { symptomatology }\end{array}$} & \multicolumn{2}{|c|}{$\begin{array}{l}\text { Live alone } \\
(\mathrm{N}=40)\end{array}$} & \multicolumn{2}{|c|}{$\begin{array}{l}\text { Lives together } \\
(\mathbf{N}=\mathbf{4 0})\end{array}$} & \multirow[t]{2}{*}{$\mathbf{P}$} \\
\hline & $\mathbf{N}$ & $\%$ & $\mathbf{N}$ & $\%$ & \\
\hline \multicolumn{6}{|l|}{ Before the prosthetic } \\
\hline $\begin{array}{l}0 \text { to } 5 \text { points - no signs of } \\
\text { depression }\end{array}$ & 22 & 55 & 27 & 67.5 & 0.5733 \\
\hline 6 to 11 - depressive signs & 16 & 40 & 10 & 25 & 0.4831 \\
\hline $\begin{array}{l}\text { Above II - severe } \\
\text { depression }\end{array}$ & 2 & 5 & 3 & 7.5 & NSA \\
\hline \multicolumn{6}{|l|}{ After the prosthetic } \\
\hline $\begin{array}{l}0 \text { to } 5 \text { points - no signs of } \\
\text { depression }\end{array}$ & 28 & 70 & 32 & 80 & 0,6119 \\
\hline 6 to 11 - depressive signs & 11 & 27.5 & 7 & 17.5 & 0.5989 \\
\hline $\begin{array}{l}\text { Above II - severe } \\
\text { depression }\end{array}$ & 1 & 2.5 & 1 & 2.5 & NSA \\
\hline
\end{tabular}

The quality of life of the two groups studied was investigated and the results obtained through the WHOQOL-Bref are presented in Table 3. Through the difference-of-proportions test, comparing the groups Vive solo and Vive accompanied at the level of significance of 0.05 , there was a significant difference in the mean response in both cases. For the test application three categories of responses were considered: Very bad + Bad, Medium and Good + Very good. Before and after the prosthesis, there were no significant differences.

Table 3 Comparison of totalWHOQOL-Bref results

\begin{tabular}{|c|c|c|c|c|c|}
\hline \multirow[t]{2}{*}{ Quality of life } & \multicolumn{2}{|c|}{$\begin{array}{l}\text { Live alone ( } N \\
=40)\end{array}$} & \multicolumn{2}{|c|}{$\begin{array}{l}\text { Lives together } \\
(\mathrm{N}=40)\end{array}$} & \multirow[t]{2}{*}{$\mathbf{P}$} \\
\hline & $\mathbf{N}$ & $\%$ & $\mathbf{N}$ & $\%$ & \\
\hline \multicolumn{6}{|c|}{ Before the prosthetic } \\
\hline Too bad & 2 & 5 & I & 2.5 & 0.5778 \\
\hline Bad & 7 & 17.5 & 6 & 15 & \\
\hline Medium & 6 & 15 & 14 & 35 & $0.0422 *$ \\
\hline Good & 16 & 40 & 11 & 27.5 & \\
\hline Very good & 9 & 22.5 & 8 & 20 & 0.1814 \\
\hline \multicolumn{6}{|c|}{ After the prosthetic } \\
\hline Too bad & 1 & 5 & I & 5 & 10,000 \\
\hline Bad & 5 & 12.5 & 5 & 12.5 & \\
\hline Medium & 5 & 12.5 & 13 & 32.5 & $0.0353 *$ \\
\hline Good & 14 & 35 & 9 & 22.5 & \\
\hline Very good & 15 & 37.5 & 12 & 30 & 0.0685 \\
\hline
\end{tabular}

*There was a statistically significant difference, since $p<0.05 \%$ 


\section{Discussion}

Advancing age brings in its wake some sensory and physical limitations, capable of damaging the old ability to remain independent. ${ }^{5}$ Among these limitations is presbycusis ${ }^{8}$ characterized by bilateral hearing loss sensorineural and downlink configuration table audiological characterized our sample.

Thanks to the technological advancement of science, people have at their disposal electronic devices such as hearing aids, which help and minimize the consequences of hearing loss ${ }^{15}$ of which lack of communication and social isolation that can lead to a depression.

Currently, the elderly living in Brazil can purchase these devices in the private network or via the Unified Health System, in services accredited to the Hearing Health Program. This government program seeks to secure with hearing loss, universal and equal access to actions and services for the promotion, protection and prevention of health..$^{11,15,16}$

The sample that participated in this study was characterized by being predominantly female, 66 to 70 years old, having a primary education degree and retired. These results are consistent with other studies on hearing health services. ${ }^{15,17,18}$ Although $85 \%$ of the sample had bilateral hearing loss, only $60 \%$ used a hearing aid in both ears. Adapt both devices is optimized therapy ${ }^{16}$ but in the elderly is common to choose only one ear due to aesthetic issues and handling device. ${ }^{19}$ In this study $90 \%$ of the sample used retroauricular prosthesis, that is, the model that is adapted behind the auditory pavilion. The BTE aids, although larger and less aesthetic are the most suitable for the elderly to facilitate the handling. ${ }^{16,19}$

The presence of depressive signs in the GDS was important in both groups surveyed in agreement with the literature, which claims to be a common sign depression in old age, people with chronic diseases and people with hearing loss., ${ }^{3,20-22}$ It is noteworthy that hearing loss impacts not only the deaf individual, but affects the family that welcomes generating communication difficulties and important relationship. ${ }^{23}$

A qualitative analysis of table 2 reveals that there was improvement of depressive signs in about $15 \%$ in the group that lives alone and $13 \%$ in the one that lives accompanied, after adaptation to the prosthesis, however this improvement was not significant. It is known that the prosthesis has proved to be a great ally in the auditory rehabilitation of the elderly. The literature states that the hearing aid helps in the recovery of hearing thresholds, improves communication condition favoring auditory discrimination, which interferes positively in the social relations of the elderly, their independence and promotes psychological issues. ${ }^{19,21}$

Most of the subjects surveyed, in both groups, reported having a good or very good quality of life. As is common society face old age as something bad and depressing ${ }^{20}$ it is also common to the elderly themselves conform disabilities inherent in the process believing that the loss of some skills is normal. ${ }^{24}$ They claim that "considering my age, my life is very good". This insight is embedded in the idea that being old is having a poor quality of life. Thus, if the elderly are in a slightly better condition than their contemporaries (many of whom have died), it is natural to feel that they have an excellent quality of life. Another factor that may have influenced this result was the data collection was performed in a hearing health service, where the users of the system were welcomed in their needs and there was satisfaction in the demands presented. The host is considered a barrier or an important facilitator in attending the user, which can cause adhesion or withdrawal of treatment. ${ }^{22}$

A qualitative analysis of table 3 reveals that in the group that lives with the quality of life improved about $5 \%$ after adapted to the prosthesis. In the group that lives alone the result was unchanged. This slight improvement was not significant, which disagrees with other studies in which the hearing aid has proved to be a tool that promotes quality of life. ${ }^{25,26}$

The fact that the elderly live alone or accompanied did not significantly influence the results of the research. However, it is known that the family, because it is the natural habitat of the human person, gives the elderly an important reference nucleus since in the extremes of life, whether in childhood or in old age, it is possible to have greater social limitation of the individual, becomes dependent on the society that surrounds..$^{27}$

Finally, it is important that geriatric depression should be seen as a heterogeneous condition resulting from several factors: social, emotional, physical, sensory, etc. ${ }^{5}$ This clinical entity, regardless of the cause, should be investigated because it interferes greatly in the quality of life of the individual point of view $w^{3,5}$ family. Presbycusis, chronic hearing loss can cause depression or aggravate $i^{8,20}$ and deserves special attention from health professionals. It is essential to value the human being in order to provide him with a successful aging.

\section{Conclusion}

The presence of depressive signs was important in the sample studied, regardless of the fact that the subjects lived alone or accompanied the use of hearing aids did not significantly influence the quality of life of the group studied.

\section{Acknowledgements}

None.

\section{Conflict of interest}

Authors declare there is no conflict of interest in composing this manuscript.

\section{References}

1. WHO. Global burden of disease. World Health Organization, Geneva, Switzerland; 2008.

2. Katon WJ. Epidemiology and treatment of depression in patients with chronic medical illness. Dialogues Clin Neurosci. 2011;13(1):7-23.

3. Borges DT, Dalmolin BM. Depression in the elderly of a community assisted by the Family Health Strategy in Passo Fundo. Brazilian Journal of Family and Community Medicine. 2012;7(23):75-82.

4. Goncalves VC, Andrade KL. Prevalence of depression in the elderly attended at a geriatric outpatient clinic in northeastern Brazil. Rev Bras Geriatr Gerontol. 2010;13(2):125-134.

5. Ribeiro RCM, Santiago E, Bertolin DC, et al. Depression in elderly patients with chronic renal failure on hemodialysis. Acta Paul Enferm. 2009;22(Eng):505-508.

6. Boing AF, Melo GR, Boing AC, et al. Association between depression and chronic diseases: population study. Rev Saúde Pública. 2012;46(4):617-623. 
7. Udupi VA, Uppunda AK, Mohan KM, et al. The relationship of perceived severity of tinnitus with depression, anxiety, hearing status, age and gender in individuals with tinnitus. Int Tinnitus J. 2013;18(1):29-34.

8. Fonseca ABM, Santos TMM, Souza AP. Hearing, cognition and speech perception in aging: evidence in the literature. Common Disorders. 2015;27(1):162-173.

9. Queiroz DS, Barreiro FC, Santos TM. Threshold of temporal auditory resolution in the elderly. Pro Fono. 2010;22(3):211-223.

10. Almeida K, Iorio MCM. Hearing aids. Lovise, São Paulo, Brazil; 2017.

11. National Health Policy of the Elderly Person. Ministry of Health, Brazil; 2007.

12. Fleck MPA, Louzada S, M Xavier, et al. Application of the Portuguese version of the abbreviated instrument of quality of life WHOQOL-Bref. Rev Saúde Pública. 2000;34(2):178-183.

13. Almeida OP, Almeida SA. Reliability of the Brazilian version of the depression scale in geriatrics (GDS) reduced version. Arq Neuropsiquiat. 1999;57(2B):421-426

14. Federal Speech Therapy Council. Tonal audiometry, logoaudiometry and acoustic immitance measurements. Brazil; 2013.

15. Ribas A, Serrato MR, Angel K. Sociohistoric profile of patients attended at the speech therapy clinic of the Tuiuti University of Paraná. Revista Biotecnologia e Saúde. 2012;5(1):13-22.

16. Fialho IM, Bortoli D, Mendonça GG, et al. Perception of the elderly about the use of hearing aid granted by the Unified Health System Rev. CEFAC. 2009;11(2):338-344

17. Guarinello AC, Cruz MCM. The profile of the elderly patients at the Tuiuti University of Paraná Clinic of Speech and Hearing Therapy. Revista Fono Atual São Paulo. 2006;8(35):59-64.
18. Jardim IS, Iwahashi JH, Paula VC. Study of the audiological profile of individuals attended at a Brazilian diagnostic service. Arq Int Otorhinolaringol. 2010;14(1):32-37.

19. Ribas A, Raquel MD, Marques JM. SOS Auditory Protesis-Report of a case study carried out at the Speech Therapy Clinic of UTP. Archives of Otorrinolringol. 2009;4(3):123-127.

20. Canineu PR. Depression in the elderly. In: Papaleo-Netto M, editors. Treatise on Gerontology, Atheneu, Brazil; 2007.

21. Barbosa SP, Elizeu TS, Penna CMM. Optics of health professionals about access to primary health care. Ciênc Collective health. 2013;18(8):2347-2357.

22. Oliveira AP, Gomes L, Oliveira RF. Prevalence of depression in elderly people attending community centers. Rev Saúde Pública. 2006;40(4):734-746.

23. Yamada MO, Bevilacqua MC. Affective dimension of people with acquired deafness before and after the use of cochlear implant. Estud Psicol. 2012;29(1):63-69.

24. Vecchia RD, Ruiz T, SCM Bocchi JE. Quality of life in the third age: a subjective concept. Rev Bras Epidemiol. 2005;8(3):246-252.

25. Teixeira AR, Almeida LG, Jotz GP, et al. Quality of life of adults and the elderly after hearing aid adaptation. Rev Soc Bras Fonoaudiol. 2008;13(4):357-361.

26. Ribas A, Kozlowski L, Almeida GV, et al. Quality of life: comparing results in the elderly with and without presbycusis. Rev Bras Geriatr Gerontol. 2014;17(2):353-362.

27. Pimenta ES. The necessary care in relation to the family, mental disorder and psychosocial care center. Knowledge and Diversity. 2012;4(7):43-54. 